\title{
Racial Disparities in the Tangible Dimension of the Public Health Care in South Africa
}

\author{
J.W. de Jager \\ A.T. Roux \\ M.S. Mokhola \\ University of Tshwane University of Technology \\ dejagerjw@tut.ac.za
}

\section{Doi:10.5901/mjss.2014.v5n27p1521}

\begin{abstract}
Health care inequality is detrimental to the wellbeing of any country, yet healthcare is not immune to the deeply rooted inequalities in society. Researchers have examined health care quality in many settings, however relatively little analysis is available on inequality in the tangible dimension provided by public hospitals in developing countries. The purpose of this study was to determine if equality exists between black- and white in-patients in terms of the service tangibility dimension. A total of five hundred and twenty five interview administrated surveys were conducted with patients of at one of the largest public hospitals in South Africa. It was found that overall the cleanliness of bedding and wards was regarded as the most important. Black in-patients as well as white in-patients expressed similar expectations. This area was also perceived as the most satisfactory. Black in-patients perceived these service areas similar while the white in-patients had a slightly different view. Clear informative signage and the visibility of staff identity were indicated at the least satisfactory. Findings of this study can contribute to addressing problem areas in service tangibly in public hospitals and to eliminate racial and ethnic disparities experienced.
\end{abstract}

Keywords: Health care quality, Racial /ethnic disparities, services cape/tangibles

\section{Introduction}

In Afghanistan, the lifetime risk of a maternal death is one in eleven women; while it is as low as one in 31800 women in Europe. This appalling premature loss of women's lives is not only due to lack of provision of skilled birth attendants, but much of it arises because of the inequitable nature of social and economic arrangements, both globally and locally (Commission on Social Determinants of Health, 2008). Kumar (2003) warns against empty promises with no actions. Thus reform is not possible without addressing the human development in the area of health to all people in a society.

Despite the focus on increased access to proper health care, challenges in the achievement of equity in service provision remain unresolved. The overall distribution of health service benefits in African countries such as Ghana, Tanzania and South Africa favour wealthy people, with the burden of illness greater for lower-income groups (Mills, Ataguba, Akazili, Borghi, Garshong, Makawia, Mtei, Harris, Macha, Meheus, \& McIntyre, 2012). India still experiences major inequity in resource allocation, limited physical access to high-quality health services and human resources for health, unaffordable health expenditures, increase in health spending, and behavioural factors that affect the demand for appropriate health care (Balarajan, Selvaraj, Subramanian, 2011).

In pursuit of the overarching goal of eliminating health disparities, all differences among populations in measures of health and health care are considered evidence of disparities (AHRQ, 2004:7). This article focusses specifically on public health care provision. Measuring health care quality stratified by race and ethnicity is the first step to reduce these disparities (Jones, Trivedi \& Ayanian, 2010:337). Interventions by health care providers to address health care inequality must not only consider the health care delivery system and some patient-level factors, but should rather be based on empirical evidence about the causes of racial and ethnic disparities in their own setting to uncover actual sources of disparities along the continuum of care (Cooper, Hill, \& Powe, 2002; van Ryn \& Fu, 2003). Without proper measurement health care providers will be unable to identify exactly where disparities exist or monitor the effectiveness of interventions on disparities. Only once health care organisations and -providers realise there are disparities in their own practices, they will become motivated to address them. It is therefore crucial for all health care organisations to collect data on their patients' race, ethnicity and language so these data are consistently available to monitor and improve disparities in the 
quality and outcomes of health care.

A number of studies on service delivery in a variety of health care settings have been published recently, such as patients' satisfaction with their access to treatment in both the public and private healthcare sectors in London (OwusuFrimpong, Nwankwo, Dason, 2010); the comparison of hospitals' quality and safety across five European countries, specifically England, Portugal, The Netherlands, Sweden and Norway (Burnett, Renz, Wiig, Fernandes, Weggelaar, Calltorp, Anderson, Vincent \& Fulop, 2013); service quality delivery across five African countries, specifically Ghana, Mozambique, Rwanda, Tanzania and Zambia (Hirschhorn, Baynes, Sherr, Chintu, Williams, Finnegan, Philips, Anatole, Bawah \& Basinga 2013); health care quality and performance across cities and rural areas in India and Iran (Gorji \& Farooqui, 2013) and a comparison between antenatal care quality in the public and private sector in rural Hebei, China (Chen, Dai, Zhang, Rudan, Saftic, van Velthoven, Su, Tan \& Scherpbier, 2012).

Some researchers have also examined the race and ethnic disparities in health care in developing countries such as the United States (Jones, Trivedi \& Ayanian, 2010:337; Jimenez, Cook Bartels \& Alegría, 2013; Palmer, Geiger, Felder, Lu, Case \& Weaver, 2013), New Zealand (Rumball-Smith, Sarfati, Hider \& Blakely, 2013) and Canada (Wardman, Clement, \& Quantz, 2005) as well as various developing countries such as India, Chile, Argentina, Brazil, Costa Rica, Ghana, and Tanzania (Balarajan, Selvaraj, Subramanian, 2011; Marmot, Allen, Bell, Goldblatt, 2012; Mills, Ataguba, Akazili, Borghi, Garshong, Makawia, Mtei, Harris, Macha, Meheus \& McIntyre 2012). However, far less research on the racial disparities with regards to tangible service delivery in public health care has been conducted in emerging markets, such as South Africa.

\section{Literature Review}

In this section, racial- and ethnic disparities in health care are discussed. Then the tangible dimension of service quality is contextualised within the health care environment, followed by a discussion on the application of service quality to address health care disparities.

\subsection{Racial and ethnic disparities in health care}

The term "inequality," when referring to the health care quality among population groups, implies not only a difference but also inequality and unfairness. Applying this term to the differences in health care between black and whites South Africans is thus inherently controversial, and it necessitates proper investigation. These differences in health care occur in the context of broader historic and contemporary social and economic inequality and ethnic and racial discrimination in some levels of the society.

It is well documented that ethnic disparities are still evident in various health care settings, despite comparable health insurance levels, income, age, and severity of health conditions. Rumball-Smith, Sarfati, Hider and Blakely (2013) compared the quality of hospital care for New Zealand Māori and New Zealand European adult patients and found ethnic disparities in the quality of hospital care indicated by the unplanned readmission or death rate as an indicator of quality.

Jimenez, Cook Bartels and Alegría (2013) measured disparities across five aspects of episodes of mental health care across: treatment initiation, adequacy of care, duration of care, number of visits and expenditures. In this study a longitudinal large-scale survey with one thousand six hundred fifty-eight participants (981 Whites, 303 Blacks, and 374 Latinos) and medical providers was conducted across the United States. Lower levels of treatment initiation and adequacy of care were reported for blacks and Latinos compared to whites. Blacks and Latinos had significantly lower number of visits that entailed mostly just refill of medication. Despite blacks having significantly greater rates of mental episodes, they were mostly treated during outpatient care visits. Latinos had significantly higher rates of medication plus outpatient visits. It is clear that low mental health treatment initiation and poor adequacy require culturally appropriate interventions to engage all groups equally in mental health care.

Palmer, Geiger, Felder, Lu, Case and Weaver (2013) scrutinised the ethnic disparities in health care among a nationally representative sample of male cancer survivors in America. Despite equal access to health care ethnic inequalities were still significant among older patients. However no ethnic inequalities were found for younger cancer survivors.

\subsection{The tangible environment of health care}

Grönroos (1982) distinguish between two dimensions of quality in health services, technical quality and functional quality. Technical quality entails the accuracy of medical diagnoses and procedures whereas functional quality refers to the way 
in which health care services are delivered to patients. Functional quality focuses on "how", and considers issues such as the behaviour of customer-contact staff and the speed of service, whereas technical quality focuses on "what" and considers such issues as the end result of service provision. Patient experience deals with all aspects of the perceptions of patients and their families and ranging from safety, quality of food, friendliness of staff; quality of food to physical surroundings. Perceptions of the physical surroundings are important due to the effect the physical evidence has on patient and on their perceptions of service quality (Harris \& Ezeh, 2008; Holder \& Berndt, 2011).

According to Rosenbaum and Massiah (2011), it is imperative for all types of service providers to appreciate how critical environmental stimuli influence the behaviour of their customers and which of these are the most influential on their response to the physical dimensions offered. The naturally restorative dimension of tangible (sometimes referred to as servicescape) can help reduce relief from mental fatigue and improve overall health and well-being. Harris and Ezeh (2008) point out that general consensus is that service settings provoke emotional responses which lead customers to either choose to continue their association with a particular service provider or to discontinue patronage (Hoffman \& Turley, 2002; Harris \& Ezeh, 2008).

Thus, public hospitals can improve the overall experience of the care offered and ultimately the quality of life of people by creating natural servicescapes that have restorative potential For the sake of clarity the tangible service offer is defined as an organisations physical facility or environment where the service is offered. Or as non-living features that comprise the service environment (Zeithaml, Bitner \& Gremler, 2006; Hofmann, Bateson, Wood \& Kenyon, 2009; Countryman \& Yang, 2006; Lovelock \& Wright, 2002; Holder \& Berndt, 2011). It is thus clear that the services that are rendered within the tangible construct (physical environment) may have a significant influence on the satisfaction levels experienced by patients in a public healthcare setting.

\subsection{Applying service quality to address health care disparities}

Customers find it difficult to discern the technical quality of high-credence properties (such as medical services) with accuracy, and therefore often rely on other measures of quality attributes - especially those associated with the process of service delivery or functional quality. Sajid and Baig (2007) claim that the satisfaction of the patient should be the most important criterion when assessing the effectiveness of all public healthcare systems worldwide. In this context, Andaleeb (2010) warns that this is often not the case in developing countries, where the service experience of patients has - to date - been largely ignored by healthcare providers. This is problematic because patients' perceptions of healthcare service quality are likely to influence their usage of the available healthcare, as well as their trust in, and attitude towards treatment. These perceptions might even result in-patients avoiding the public healthcare system or availing themselves of such services, only as a measure in last resort. Although patient satisfaction should not be the only criterion when evaluating service quality, it offers valuable information associated with customer retention and patients' wants and needs.

Investigating patients' satisfaction with healthcare services is seen as a vital and useful tool for the optimum evaluation of healthcare providers. Healthcare quality in the developing countries should be improved for the following reasons: increasing patient dissatisfaction with higher costs (mainly in private hospitals), low quality in public healthcare services, raising service quality in order to increase the income of health workers, the necessity to increase the efficiency and effectiveness of healthcare management, to reduce the exploitation and misuse of medication and medical treatments - as well as the need to adhere to basic humanitarian principles (Øvretveit, 2004).

The phenomenon of consumers being swayed by tangible factors is common in both emerging and developed countries. This can be seen in the case of Belgium where customer satisfaction is based on factors such as empathy, assurance and tangibles such as the look and feel of an establishment. An experienced patient is able to evaluate the service that was provided to them in terms of the course of their treatment (De Jager \& du Plooy, 2007). In addition Butt and de Run (2008) is of the view that a satisfied customer is more likely to continuously use the service, spread positive views which benefit such facility with less effort and cost than new customers. This consequently gave rise to studies related to service quality.

The use of service quality as a concept has aroused considerable interest and debate in the research literature, because of the difficulties in both defining it and measuring it with no overall consensus emerging on either (Parasuraman et al., 1985). SERVQUAL, which is the widely used model of service quality, focuses on the functional-quality dimension. This model, views service quality as the gap between the expected level of service and customer perceptions of the level received (Parasuraman et al., 1988). SERVQUAL identified five determinants of service quality: reliability; assurance; tangibles; empathy; and responsiveness.

Conceptually, these constructs address, respectively, performance standards, expertise and physical elements of 
the facility, employees. (Parasuraman, et al., 1988:35-43). This article focuses in the "tangibles" dimension of service quality.

SERVQUAL is widely used by academics and practitioners to measure service quality (Wong, 2002; Youssef, Nel \& Bovaird, 1996; Sewel, 1997; Jabnoun \& Chaker, 2003). Although all five SERVQUAL dimensions were measured for the public hospital in this study, only the tangible construct is analysed for the purposes of this article. The tangible dimension includes aspects such as cleanliness and appearance of health care facilities including the equipment (Sajid \& Baig, 2007; Berry \& Parasuraman, 1991).

The physical service environment plays a significant role in customers' evaluation of their service experience, and influences their evaluation of the service delivery as well as service quality perceptions. Physical aspects largely influence the opinions of customers when assessing intangible goods or services since they often find components of service delivery too complex to evaluate.

In the following sections, the purpose, methodology and findings of the research will be presented.

\section{Research Purpose}

The purpose of this study is to examine racial disparities in the service scape of a public hospital in South Africa.

The specific objectives of the study are as follows:

- To determine if equality exists between black and white in-patients for the service tangibility (service scapes) provided to patients in a public hospital in South Africa (expectations).

- To determine if equality exists between black and white in-patients for the service tangibility (service scapes) provided to patients in a public hospital in South Africa (perceived performance).

- To determine whether the expectations of black and white in-patients in terms of the tangible variables are met (satisfaction).

In-patients refer to patients admitted to and treated in the hospital. The service tangible construct under investigation includes the variables as indicated in Table 1

\section{Research Methodology}

\subsection{Research design and instrument}

A quantitative strategy of inquiry in the form of a survey research was used for this study.

A structured questionnaire, based on the one developed by Babakus and Mangold (1992) was used to develop a measurement instrument. However this had to be adapted for the South African public health care environment. This was done based on the input of one manager and one medical professional from a large public hospital in South Africa. They suggested that some additional variables must be included to accurately measure the tangible dimension in a public hospital settings, such as the visibility of staff identity, noise level of corridors and wards, general state of bedding and quantity of food. Finally a total of 18 items were used to measure the service tangibles of the hospital.

The measuring instrument was designed in such a manner as to enable the researchers to test the formulated hypothesis based on the two formulated assumptions. Only the relevant aspects for this article will be reported, namely:

- The perceptions of black and white in-patients regarding their expectations of the hospital's tangible service variables and

- The perceptions of patients regarding the hospital's tangible related services performance.

The two dimensions represented a mirror-image of each other. A five -point Likert type scale was used to measure the levels of perceived performance of the hospitals as well as the expectation levels of the patients.

Respondents were asked to indicate their evaluation on the scales in which: $1=$ Very important (Excellent), $2=$ Important (Good), $3=$ Not important nor unimportant (Neither good nor bad), $4=$ Not important (Not good), $5=$ Not important at all (Not good at all.)

A pilot test of the questionnaire was done amongst a sample of 30 patients, allowing for consideration of the length of the questionnaire, clarity of instructions, lay-out the and flow of questions.

An item analysis was carried out to test the validity and the reliability of the questionnaire and an overall Cronbach coefficient Alpha of 0.9453 and 0.9122 were measured for expectations and performance respectively. 


\subsection{The sample and data collection}

A realized sample size of 525 in-patients in the hospital, distributed between 320 black respondents and 205 white respondents, was obtained from a target sample size of 550 , with $100 \%$ of these questionnaires being usable. This could be attributed to the use of trained and supervised fieldworkers to collect the data.

The attitudes of the patients regarding the pre-identified service quality aspects related to health care in public hospitals were tested. Although an attempt was made to select the patients randomly to represent all the wards in the hospital, it was not always possible due to patients that were not able and/or willing to complete the questionnaires. In such cases substitutes were selected to overcome the problem of no responses.

\subsection{Hypothesis}

Three primary hypotheses were tested namely:

\subsubsection{Hypothesis 1}

- $\mathrm{H}_{01}$ : Black and white in-patients have the same level of expectations with regard to hospital tangibility variables.

- $\mathrm{H}_{\mathrm{a} 1}$ : Black and white in-patients have different levels of expectations with regard to hospital tangibility variables.

If the $\mathrm{H}_{01}$ hypothesis is accepted then it can be assumed that all patients expect the same level of treatment with regards to tangible hospital offerings. On the other hand, if the $\mathrm{H}_{01}$ hypothesis is rejected then, it is assumed black- and white in-patients differ in terms of their expectations.

\subsubsection{Hypothesis 2}

- $\mathrm{H}_{02}$ : There are no significant differences between black and white in-patients with regard to the perceived performance of the hospital in terms of tangible hospital services.

- $\mathrm{H}_{\mathrm{a} 2}$ : There exist significant differences between black and white in-patients with regard to the perceived performance of the hospital in terms of tangible hospital services.

If the $\mathrm{H}_{02}$ hypothesis is accepted then it can be assumed that all patients expect the same level of treatment with regards to tangible hospital offerings. On the other hand, if the $\mathrm{H}_{02}$ hypothesis is rejected then, it is assumed black- and white in-patients differ in terms of their expectations.

\subsubsection{Hypotheses 3}

- $\mathrm{H}_{03}$ : There exist no statistical significant differences between in-patients level of satisfaction with regard tangible hospital services.

- $\mathrm{H}_{\mathrm{a} 3}$ : There exist statistical significant differences between in-patients satisfaction with regard to the tangible hospital services.

If the $\mathrm{H}_{03}$ hypothesis is accepted then it implies that the expectations of patients are met, leading to a feeling of satisfaction. On the other hand, if the $\mathrm{H}_{03}$ hypothesis is rejected, then it is assumed that patients expectations are not met which may lead to a feeling of dissatisfaction.

The null hypothesis was tested at a 0.05 significance level.

\subsection{Assumptions}

Based on the discussion of health care inequality the researchers are of the opinion that the following assumptions can be deducted for this study:

- All health care providers should deliver health care that does not vary in quality because of characteristics such as gender, ethnicity, geographic location, and socioeconomic status. This should be the case at the population and individual levels, so that health disparities among populations are reduced.

- If a spirit of Equitable service prevails then patients will be treated in an equitable manner regardless gender, 
race or culture.

In-patients refer to patients admitted to and treated in the hospital. The service tangible construct under investigation includes the variables as indicated in Table 1

\subsection{Data Analysis}

Data was captured by a trained assistant and analysed using the SPSS version 21 statistical package. Data was analysed after grouping the list of pre-identified service related variables into five service related groupings.

A non-parametric test, the Kruskal-Wallis test was done to test the null hypothesis and the alternative hypothesis of the three hypotheses.

\section{Findings}

For the purpose of the discussion the expectations of patients, their perceived performance as well as their rate of satisfaction regarding the tangible health care services were reported in one table.

As can be seen in table 1, the patients reported fairly high expectations on the majority of the tangibility variables as opposed to the relatively low expectations reported by the study of Sohail (2003). This suggests that all patients demand excellent tangibility levels. The three most important issues (in terms of their expectations) for patients in general are:

- Cleanliness of bedding (Mean: 1.52)

- Cleanliness of wards (Means: 1.57)

- Cleanliness of ablution facilities (Mean: 1.60)

Table 1: Differences between expectations and perceived performance of tangibility

\begin{tabular}{|c|c|c|c|c|c|c|c|c|c|c|c|}
\hline & \multicolumn{4}{|c|}{ Black In-patients } & \multicolumn{4}{|c|}{ White In-patients } & \multicolumn{3}{|c|}{ Total In-patients } \\
\hline Tangibility: & Exp Mear & If Mean & Gap & ired sample & Exp Mea & rf Mea & Gap & ired sample & Exp Mea & $\mathrm{rfmec}$ & Gap \\
\hline General condition of equipment & $\begin{array}{c}1.57 \\
3\end{array}$ & $\begin{array}{c}1.84 \\
4\end{array}$ & $\begin{array}{c}-0.27 \\
11\end{array}$ & 0.0001 & $\begin{array}{c}1.71 \\
5\end{array}$ & $\begin{array}{c}2.20 \\
4\end{array}$ & \begin{tabular}{|c|}
-0.49 \\
7
\end{tabular} & 0.0001 & $\begin{array}{c}1.62 \\
4\end{array}$ & $\begin{array}{c}1.96 \\
3\end{array}$ & $\begin{array}{c}-0.34 \\
8\end{array}$ \\
\hline Visual appearance of Physical facilities & $\begin{array}{c}1.90 \\
13\end{array}$ & $\begin{array}{c}2.11 \\
11\end{array}$ & $\begin{array}{c}-0.21 \\
7\end{array}$ & 0.0001 & $\begin{array}{c}2.01 \\
12\end{array}$ & $\begin{array}{c}2.53 \\
12 \\
\end{array}$ & $\begin{array}{c}-0.52 \\
9 \\
\end{array}$ & 0.0001 & $\begin{array}{c}1.93 \\
13\end{array}$ & $\begin{array}{c}2.25 \\
10\end{array}$ & $\begin{array}{c}-0.32 \\
7 \\
\end{array}$ \\
\hline Neat appearance of staff & $\begin{array}{c}1.80 \\
1\end{array}$ & $\begin{array}{c}1.87 \\
6\end{array}$ & $\begin{array}{c}-0.07 \\
2\end{array}$ & 0.0001 & $\begin{array}{c}1.83 \\
7\end{array}$ & $\begin{array}{c}2.26 \\
5\end{array}$ & \begin{tabular}{|c|}
-0.43 \\
3
\end{tabular} & 0.0001 & $\begin{array}{c}1.81 \\
9\end{array}$ & $\begin{array}{c}2.00 \\
5\end{array}$ & $\begin{array}{c}-0.19 \\
3\end{array}$ \\
\hline Convenience of parking & $\begin{array}{c}2.45 \\
18\end{array}$ & $\begin{array}{c}2.76 \\
18\end{array}$ & \begin{tabular}{|c|}
-0.31 \\
12
\end{tabular} & 0.0001 & $\begin{array}{c}2.18 \\
17\end{array}$ & $\begin{array}{c}3.15 \\
18\end{array}$ & \begin{tabular}{|c|}
-0.97 \\
17
\end{tabular} & 0.0001 & $\begin{array}{c}2.35 \\
18\end{array}$ & $\begin{array}{c}2.91 \\
18\end{array}$ & $\begin{array}{c}-0.56 \\
16\end{array}$ \\
\hline Availability of adequate seating & $\begin{array}{c}2.02 \\
16\end{array}$ & $\begin{array}{c}2.37 \\
15\end{array}$ & \begin{tabular}{|c|}
-0.35 \\
14
\end{tabular} & 0.0001 & $\begin{array}{c}2.10 \\
15\end{array}$ & $\begin{array}{c}2.70 \\
15 \\
\end{array}$ & \begin{tabular}{|c|}
-0.6 \\
10 \\
\end{tabular} & 0.0001 & $\begin{array}{c}2.05 \\
16\end{array}$ & $\begin{array}{c}2.48 \\
15\end{array}$ & \begin{tabular}{|c|}
-0.43 \\
13 \\
\end{tabular} \\
\hline Quality of cafeteria services & $\begin{array}{c}2.22 \\
17\end{array}$ & $\begin{array}{c}2.40 \\
16\end{array}$ & $\begin{array}{c}-0.18 \\
6\end{array}$ & 0.0001 & $\begin{array}{c}2.19 \\
18\end{array}$ & $\begin{array}{c}2.66 \\
14\end{array}$ & \begin{tabular}{|c|}
-0.47 \\
5
\end{tabular} & 0.0001 & $\begin{array}{c}2.21 \\
17\end{array}$ & $\begin{array}{c}2.49 \\
16\end{array}$ & $\begin{array}{c}-0.28 \\
6 \\
\end{array}$ \\
\hline Cleanliness of ablution facilities & $\begin{array}{c}1.63 \\
4\end{array}$ & $\begin{array}{c}2.10 \\
10\end{array}$ & $\begin{array}{c}-0.47 \\
16\end{array}$ & 0.0001 & $\begin{array}{c}1.53 \\
2\end{array}$ & $\begin{array}{c}2.73 \\
16\end{array}$ & \begin{tabular}{|c|}
-1.2 \\
18
\end{tabular} & 0.0001 & $\begin{array}{c}1.60 \\
3\end{array}$ & $\begin{array}{c}2.32 \\
13\end{array}$ & \begin{tabular}{|c|}
-0.72 \\
18
\end{tabular} \\
\hline Clear and informative signage & $\begin{array}{c}1.98 \\
15\end{array}$ & $\begin{array}{c}1.97 \\
7\end{array}$ & $\begin{array}{c}0.01 \\
1\end{array}$ & 0.0001 & $\begin{array}{c}1.93 \\
11\end{array}$ & $\begin{array}{c}2.38 \\
8\end{array}$ & $\begin{array}{c}-0.45 \\
4\end{array}$ & 0.0001 & $\begin{array}{c}1.96 \\
14\end{array}$ & $\begin{array}{c}2.10 \\
8\end{array}$ & $\begin{array}{c}-0.14 \\
1\end{array}$ \\
\hline Visibility of Staff identity & $\begin{array}{c}1.70 \\
7\end{array}$ & $\begin{array}{c}1.83 \\
3\end{array}$ & \begin{tabular}{|c|}
-0.13 \\
3
\end{tabular} & 0.0001 & $\begin{array}{c}2.17 \\
16\end{array}$ & $\begin{array}{c}2.38 \\
8\end{array}$ & $\begin{array}{c}-0.21 \\
1\end{array}$ & 0.0001 & $\begin{array}{c}1.86 \\
12\end{array}$ & $\begin{array}{c}2.01 \\
6\end{array}$ & $\begin{array}{c}-0.15 \\
2\end{array}$ \\
\hline Cleanliness of corridors & $\begin{array}{c}1.68 \\
5\end{array}$ & $\begin{array}{c}1.84 \\
4\end{array}$ & \begin{tabular}{|c|}
-0.16 \\
5
\end{tabular} & 0.0001 & $\begin{array}{c}1.84 \\
9\end{array}$ & $\begin{array}{c}2.31 \\
6\end{array}$ & \begin{tabular}{|c|}
-0.47 \\
5
\end{tabular} & 0.0001 & $\begin{array}{c}1.73 \\
6\end{array}$ & $\begin{array}{c}1.99 \\
4\end{array}$ & $\begin{array}{c}-0.26 \\
4\end{array}$ \\
\hline Noise level of corridors & $\begin{array}{c}1.93 \\
14\end{array}$ & $\begin{array}{c}2.16 \\
12\end{array}$ & $\begin{array}{c}-0.23 \\
9\end{array}$ & 0.0001 & $\begin{array}{c}2.04 \\
14\end{array}$ & $\begin{array}{c}2.75 \\
17\end{array}$ & \begin{tabular}{|c|}
-0.71 \\
16
\end{tabular} & 0.0001 & $\begin{array}{c}1.97 \\
15\end{array}$ & $\begin{array}{c}2.36 \\
14\end{array}$ & \begin{tabular}{|c|}
-0.39 \\
12
\end{tabular} \\
\hline Noise level of wards & $\begin{array}{c}1.83 \\
12\end{array}$ & $\begin{array}{c}2.04 \\
8\end{array}$ & \begin{tabular}{|c|}
-0.21 \\
7
\end{tabular} & 0.0001 & $\begin{array}{c}1.83 \\
7\end{array}$ & $\begin{array}{c}2.43 \\
10\end{array}$ & \begin{tabular}{|c|}
-0.6 \\
10 \\
\end{tabular} & 0.0001 & $\begin{array}{c}1.83 \\
11\end{array}$ & $\begin{array}{c}2.17 \\
9\end{array}$ & $\begin{array}{c}-0.34 \\
8\end{array}$ \\
\hline Cleanliness of wards & $\begin{array}{c}1.55 \\
2 \\
\end{array}$ & $\begin{array}{c}1.68 \\
1 \\
\end{array}$ & \begin{tabular}{|c|}
-0.13 \\
3 \\
\end{tabular} & 0.0001 & $\begin{array}{c}1.60 \\
3 \\
\end{array}$ & $\begin{array}{c}2.11 \\
3 \\
\end{array}$ & \begin{tabular}{|c|}
-0.51 \\
8 \\
\end{tabular} & 0.0001 & $\begin{array}{c}1.57 \\
2 \\
\end{array}$ & $\begin{array}{c}1.83 \\
1\end{array}$ & \begin{tabular}{|c}
-0.26 \\
4 \\
\end{tabular} \\
\hline Cleanliness of bedding & $\begin{array}{c}1.53 \\
1\end{array}$ & $\begin{array}{c}1.78 \\
2\end{array}$ & $\begin{array}{c}-0.25 \\
10\end{array}$ & 0.0001 & $\begin{array}{c}1.49 \\
1\end{array}$ & $\begin{array}{c}2.09 \\
2\end{array}$ & $\begin{array}{c}-0.6 \\
10\end{array}$ & 0.0001 & $\begin{array}{c}1.52 \\
1\end{array}$ & $\begin{array}{c}1.88 \\
2\end{array}$ & $\begin{array}{c}-0.36 \\
11\end{array}$ \\
\hline General state of bedding & $\begin{array}{c}1.73 \\
8\end{array}$ & $\begin{array}{c}2.05 \\
9\end{array}$ & \begin{tabular}{|c|}
-0.32 \\
13 \\
\end{tabular} & 0.0001 & $\begin{array}{c}1.64 \\
4\end{array}$ & $\begin{array}{c}2.03 \\
1\end{array}$ & $\begin{array}{c}-0.39 \\
2\end{array}$ & 0.0001 & $\begin{array}{c}1.70 \\
5\end{array}$ & $\begin{array}{c}2.04 \\
7\end{array}$ & \begin{tabular}{|c}
-0.34 \\
8
\end{tabular} \\
\hline Serving temperature of food & $\begin{array}{c}1.77 \\
9 \\
\end{array}$ & $\begin{array}{c}2.21 \\
13\end{array}$ & \begin{tabular}{|c|}
-0.44 \\
15
\end{tabular} & 0.0001 & $\begin{array}{c}1.82 \\
6 \\
\end{array}$ & $\begin{array}{c}2.48 \\
11\end{array}$ & \begin{tabular}{|c|}
-0.66 \\
14 \\
\end{tabular} & 0.0001 & $\begin{array}{c}1.79 \\
7 \\
\end{array}$ & $\begin{array}{c}2.30 \\
11\end{array}$ & \begin{tabular}{|c|}
0.51 \\
15 \\
\end{tabular} \\
\hline
\end{tabular}




\begin{tabular}{|c|c|c|c|c|c|c|c|c|c|c|}
\hline & \multicolumn{3}{|c|}{ Black In-patients } & \multicolumn{4}{|c|}{ White In-patients } & \multicolumn{3}{|c|}{ Total In-patients } \\
\hline Tangibility: & Exp Mean Prf Mea & Gap & aired sample & Exp Mez & rf Mea & Gap & ired sample & Exp Mea & rf Mea & Gap \\
\hline Tastefulness of food & \begin{tabular}{|c|c|}
1.79 & 2.50 \\
10 & 17 \\
\end{tabular} & \begin{tabular}{|c|}
-0.71 \\
18
\end{tabular} & 0.0001 & $\begin{array}{c}1.89 \\
10\end{array}$ & $\begin{array}{c}2.59 \\
13\end{array}$ & \begin{tabular}{|c|}
-0.7 \\
15
\end{tabular} & 0.0001 & $\begin{array}{c}1.82 \\
10\end{array}$ & $\begin{array}{c}2.53 \\
17\end{array}$ & $\begin{array}{c}-0.71 \\
17\end{array}$ \\
\hline Quantity of food & $\begin{array}{c}2.30 \\
14\end{array}$ & \begin{tabular}{|c|}
0.61 \\
17
\end{tabular} & 0.0001 & $\begin{array}{c}2.03 \\
13\end{array}$ & $\begin{array}{c}2.31 \\
6\end{array}$ & \begin{tabular}{|c|}
-0.6 \\
10 \\
\end{tabular} & 0.0001 & $\begin{array}{c}1.80 \\
8\end{array}$ & $\begin{array}{c}2.30 \\
11\end{array}$ & \begin{tabular}{|c|}
-0.5 \\
14 \\
\end{tabular} \\
\hline Total Tangibility: & & & & & & & & & & \\
\hline
\end{tabular}

From the 18 variables measuring expectations, only six of them showed significant statistical differences between white and black respondents. The items were convenience of parking, cleanliness of ablution; visibility of staff identity; noise levels of corridor; cleanliness of bedding; and quality of food. This implies that both samples express similar expectations regarding the service offering. However the black sample overall expressed slightly higher levels of expectations compared to the white sample.

Thus of the three most important variables, the first and last reported significant differences between the white and black sample.

When considering the perceived performance of the service provider the cleanliness of the wards was overall perceived best in the tangibility category. It was rated first by the black sample and third by the white sample. Significant differences are measured between the two sample groups with blacks perceiving it significantly better compared to the white sample. In addition a significantly higher level of consensus amongst black respondents is measured. The second overall best perceived variable is the cleanliness of the bedding. Again significant differences are measured between the two sample groups with black respondents perceiving it significantly better compared to the white respondents (both rated in second position) while a significant higher level of consensus is also measured amongst the black sample.

The variable in the tangibility category that is overall perceived worst is convenient parking. Significant differences amongst respondents are measured with white respondents perceiving it significantly more negative (although both rated in $18^{\text {th }}$ position) compared to the black respondents.

In terms of the overall perceived performance of the service provider all of the variables showed statistical significant differences between black and white respondents except two variables, namely general state of the bedding and the quality of the food. This implies that for most of the variables black respondents perceived the services rendered by the service provider much better compared to their white counterparts.

The last column reveals that significant differences exist between expectations and perceived performance for both black and white patients on all tangible variables. This is an indication that expectations have generally not been met on the majority of services.

The overall smallest gap measured in the tangibility category is clear and information signage. This is the only variable in the study where any sample group, in this case, black respondents, are satisfied with a particular variable (although within a very small margin). This finding is based on the mean ratings. Statistical significant differences however were measured between the expectations and the perceived performance, resulting in dissatisfaction. This variable is however overall rated fourteenth in terms of importance.

The second smallest gap is measured in terms of visibility of staff identity. Black respondents are significantly less dissatisfied compared to white respondents. This variable is however rated thirteenth in terms of importance.

The variables that are rated three most important variables in the tangible category are however related to hygiene related issues. The biggest overall deviation between expectations and perceived performance is measured in terms of cleanliness of ablution facilities. This variable was rated fourth in terms of importance.

\section{Conclusion and Recommendations}

There is consensus between black and white respondents in terms of their expectations of tangible health care services offered in a public hospital. Thus they are expecting similar service levels though one third of all the variables measured for expectations showed significant statistical differences between white and black respondents. These variables were convenience of parking, cleanliness of ablution; visibility of staff identity; noise levels of corridor; cleanliness of bedding; and quality of food. The black sample expressed significantly higher levels of expectations compared to the white sample regarding the Visibility of staff identity; Noise levels of corridors and Quantity of food. Visibility of staff identity seems to be an important aspect contributing to safety and security in the public hospital environment. The phenomenon of noise levels of corridors that is more important for on population group compared to another is difficult to explain as it should be a key aspect amongst sick people. Quantity of food contributes to the overall feeling of well-being of patients from 
disadvantaged groups often experiencing hunger on a daily basis.

The white population expressed significantly higher expectations in terms of Convenience of parking; Cleanliness of ablution facilities and Cleanliness of bedding. Convenience of parking is typically more important to the white population group in South Africa. This makes sense since the majority of black people in the lower income groups of South Africa do not make use of private transport. A potential explanation for the higher expectations regarding cleanliness of ablution facilities and Cleanliness of bedding is that white South Africans might be used to better facilities at their own homes.

In examining of the perceived performance of the service provider an interesting phenomenon was revealed: it was clear that black respondents perceived the tangible services rendered significantly better compared to their white counterparts. Inequality thus exists between the two racial groups regarding most variables excluding, General state of bedding and the Quantity of the food. An explanation for this can be that because of unacceptable treatment towards the black population group in the past, these sample elements might be more appreciative towards the services offered to them. In contrast the white population group might experience the offering as inferior compared to what they have used to receive in terms of public medical treatment. This phenomenon should be explored in more detail to determine the actual reasons thereof.

The identified areas of inequity as well as the gaps in service delivery should be addressed. Cleanliness of ablution facilities is a critical area due to potential spreading of germs and other negative impacts of patients' health. The serving temperature, tastefulness and quantity of the food served in the hospital also needs immediate attention. Addressing inequality in health service is not insurmountable, although it will require long-term action and commitment. It will thus also be valuable to analyse other dimensions of service quality for inequality in the near future.

\section{References}

AHRQ. (2004). National Healthcare Disparities Report, Rockville, MD: Agency for Healthcare Research and Quality.

Andaleeb, S.S. (2001). Service-quality perceptions and patient satisfaction: a study of hospitals in the developing countries. Social Science \& Medicine, 52 (9), 1359-1370.

Babakus, E., \& Mangold, W. G. (1992). Adapting the SERVQUAL scale to hospital services: an empirical investigation. Health services research, 26(6), 767.

Balarajan, Y., Selvaraj, S., \& Subramanian, S. V. (2011). Health care and equity in India. The Lancet, 377(9764), 505-515.

Berry, L. \& Parasuraman, A. (1991). Marketing services. Competing through quality. The Free Press, New York, NY.

Burnett, S., Renz, A. Wiig, S., Fernandes, A., Weggelaar, A.M., Calltorp, J., Anderson, J.E., Robert, G., Vincent, C. \& Fulop, N. (2013). Prospects for comparing European hospitals in terms of quality and safety: lessons from a comparative study in five countries' International journal for quality in health care. Journal of the International Society for Quality in Health Care / ISQua, 25 (1), 1-7.

Butt, M. \& de Run. C. E. (2008). Private Health Care Quality: Applying a Service SERVQUAL Model. International Journal of Health Care Quality Assurance, 23 (7), 658- 672.

Chen, L., Y. Dai, Y. Zhang, Q. Wu, D. Rudan, V. Saftic, M. H., van Velthoven, J. Su, Z. T. \& Scherpbier, R.W. 2013. A comparison between antenatal care quality in public and private sector in rural Hebei, China. Croatian medical journal, 54 (2), 146-156. http://neuron.mefst.hr/docs/CMJ/issues/2013/54/2/ cmj_54_2_chen_23630142.pdf

Commission on Social Determinants of Health. (2008). Closing the gap in a generation: health equity through action on the social determinants of health. Final report of the Commission on Social Determinants of HealthWorld Health Organization, Geneva

Cooper, L. A., Hill, M. N. \& Powe, N. R. (2002). Designing and evaluating interventions to eliminate racial and ethnic disparities in health care. Journal of General Internal Medicine, 17(6), 477-486.

Countryman, C.C. \& Jang, H. (2006). The effects of atmospheric elements on customer impression: the case of hotel lobbies. International Journal of Contemporary Hospitality Management, 18 (7), 534-545.

De Jager, J.W. \& Du Plooy, A.T. (2007). Measuring tangibility and assurance as determinants of service quality for public health care in South Africa. Acta Commercii, 7, 96-111.

Gorji, A. M. H. \& Farooquie, J. A. (2011). A comparative study of total quality management of health care system in India and Iran. BMC research notes, 4(1), 566.

Grönroos, C. (1982). Strategic Management and Marketing in Service Sector, Marketing Science Institute, Cambridge, MA.

Harris, L.C. \& Ezeh, C. (2008). Servicescape and loyalty intentions: an empirical investigation. S. European Journal of Marketing, 42 no $3 / 4,390-422$.

Hirschhorn, L. R., Baynes, C., Sherr, K., Chintu, N., Awoonor-Williams, J. K., Finnegan, K. \& Basinga, P. (2013). Approaches to ensuring and improving quality in the context of health system strengthening: a cross-site analysis of the five African Health Initiative Partnership programs. BMC health services research, 13(Suppl 2), S8.

Hoffman, K.D., Bateson, J.E.G., Wood, E.W. \& Kenyon, A.J. (2009). Service marketing concepts, strategies and cases, South -Western CengageLearning, Australia.

Hoffman, K.D. \& Turley, L.W. (2002). Atmosperics, service encounters and customer decision making: an integrative approach. Journal of Marketing theory and practice. , Summer 2002, 33-46. 
Holder, M. \& Berndt, A. (2011). The effect of changes in servicescapes and service quality perceptions in a maternity unit. International Journal of Health care Quality Assurance, 24 (5), 389-405.

Jabnoun, N. \& Chaker, M. 2003. Comparing the quality of private and public hospitals. Managing Service Quality, 13 (4), $290-299$.

Jimenez, D. E., Cook, B., Bartels, S. J. \& Alegría, M. (2013). Disparities in mental health service use of racial and ethnic minority elderly adults. Journal of the American Geriatrics Society, 61(1), 18-25.

Jones, R. G., Trivedi, A. N. \& Ayanian, J. Z. (2010). Factors influencing the effectiveness of interventions to reduce racial and ethnic disparities in health care. Social science \& medicine, 70(3), 337-341.

Kumar, S. S. (2003). Human Development Challenges in Afghanistan: Health, Education, Women and Child:"Many Promises But no Actions'. India Quarterly: A Journal of International Affairs, 59(1-2), 261-272.

Lovelock, C.H. \& Wright, L. 2002. Principles of service marketing and management, 2nd edition, Prentice Hall, Upper Sadle River, NJ.

Macha, J., Meheus, F., \& McIntyre, D. (2012). Equity in financing and use of health care in Ghana, South Africa, and Tanzania: implications for paths to universal coverage. The Lancet, 380(9837), 126-133.

Marmot, M., Allen, J., Bell, R., \& Goldblatt, P. (2012). Building of the global movement for health equity: from Santiago to Rio and beyond. The Lancet, 379(9811), 181-188.

Mills, A., Ataguba, J. E., Akazili, J., Borghi, J., Garshong, B., Makawia, S., Mtei, G., Harris, B.,

Øvretveit, J. 2004. Formulating a health quality improvement strategy for a developing country. International Journal of Health Care Quality Assurance, 17(7), 368-376.

Owusu-Frimpong, N., Nwankwo, S. \& Dason, B. (2010). Measuring service quality and patient satisfaction with access to public and private healthcare delivery. International Journal of Public Sector Management, 23(3), 203-220.

Palmer, N. R., Geiger, A. M., Felder, T. M., Lu, L., Case, L. D. \& Weaver, K. E. (2013). Racial/Ethnic Disparities in Health Care Receipt Among Male Cancer Survivors. American journal of public health, 103(7), 1306-1313.

Parasuraman, A. Zeithaml, V.A. \& Berry, L.L. (1988). Servqual: a multi item scale for measuring customer perceptions of service quality. Journal of retailing, 64 (1), 12-37.

Parasuraman, A. Berry, L.L. \& Zeithaml,V.A. (1985). A conceptual model of service quality and its implications for future research. Journal of Marketing, 49 (3), 41-50.

Rosenbaum, M. S., \& Massiah, C. (2011). An expanded servicescape perspective. Journal of Service Management, 22(4), $471-490$.

Rumball-Smith, J., Sarfati, D., Hider, P., \& Blakely, T. (2013). Ethnic disparities in the quality of hospital care in New Zealand, as measured by 30-day rate of unplanned readmission/death. International journal for quality in health care, 25(3), 248-254.

Sajid, M.S. \& Baig, M.K. (2007). Quality of health care: an absolute necessity for public satisfaction. International Journal of Health Care Quality Assurance, 20(6), 545 - 548.

Sewell, N. (1997). Continuous quality improvement in acute healthcare: creating a holistic and integrated approach, International Journal of Healthcare Quality Assurance, 10(1), 20-26.

Wardman, D., Clement, K. \& Quantz, D. (2005). Access and utilization of health services by British Columbia's rural Aboriginal population. Leadership in Health Services, 18(2): $26-31$.

Youssef, F., Nel, D. \& Bovaird, T. (1995). Service quality in NHS hospitals. Journal of Management in Medicine, 9 (1), 66-74.

Zeithaml, V.A., Bitner, M.J. \& Gremler, D.D. (2006). Service marketing: Integrating customer focus across the Firm, McGraw Hill, Boston. MA. 